\title{
Овощеводство Республики Беларусь
}

\author{
Vegetable growing of the Republic of Belarus
}

Аутко А.А., Бутов И.С.

\section{Аннотация}

Овощеводство Республики Беларусь в последние годы показывает высокую динамику развития. Природно-климатические условия Беларуси благоприятны для возделывания холодостойких овощных культур (все виды капусты, столовые корнеплоды, зеленные). Условия для ежегодных гарантированных сборов теплолюбивых культур (томат, огурец) в открытом грунте имеются только в юго-восточных и юго-западных районах республики. На остальной территории гарантированные урожаи этих культур наиболее возможны в теплицах, под пленочными укрытиями и в утепленном грунте. В Республике Беларусь посевные площади под овощами в последние годы во всех категориях хозяйств стабилизировались на уровне 65-70 тыс. га, в том числе в хозяйствах населения - 46-50 тыс. га, в КФХ - 10-11 тыс. га. В последние 20 лет прослеживается положительная тенденция поступательного наращивания производства в КФХ, урожайность овощной продукции в которых в 2018 году на 64 и 31\% превышала аналогичный показатель по с.-х. организациям и хозяйствам населения соответственно. В общей структуре валового сбора овощей на хозяйства населения приходится порядка 67-69\%, КФХ - 16-19\%, с.-х. организации $-13-15 \%$. Производство овощей на душу населения в последние годы колебалось на уровне 178-206 кг (при норме 146 кг). Республика полностью обеспечивает себя овощами, кроме того овощи поставляются на экспорт. В стране построено более 60 современных овощехранилищ, однако большинство из них требует существенной реконструкции. В настоящее время отмечен также рост производства плодоовощных консервов. Таким образом, внутренний рынок овощей полностью обеспечен продукцией собственного производства. Для повышения эффективности овощеводства Республики Беларусь на основе специализации и концентрации производства необходимо совершенствование организации всего овощного подкомплекса, включающую территориальное размещение, специализацию и структуру производства овощей, в том числе укрепление материально-технической базы переработки и хранения, улучшение организации закупок товарной продукции, расширение ассортимента и улучшение качества овощей.

Ключевые слова: Республика Беларусь, овощеводство, овощной подкомплекс, с.-х. организации, КФХ, хозяйства населения.

Для цитирования: Аутко А.А., Бутов И.С. Овощеводство Республики Беларусь // Картофель и овощи. 2020. №2. С.12-15. https://doi.org/10.25630/PAV.2020.18.2.002
Autko A.A. , Butov I.S.

\section{Abstract}

Vegetable growing in the Republic of Belarus in recent years shows a high dynamics of development. The natural and climatic conditions of Belarus are favorable for the cultivation of coldresistant vegetable crops (all types of cabbage, table roots, green). Conditions for annual guaranteed collections of heat-loving crops (tomato, cucumber) in the open ground are available only in the South-Eastern and South-Western regions of the Republic. In the rest of the territory, guaranteed yields of these crops are most possible in greenhouses, under film shelters and in insulated soil. In the Republic of Belarus, the sown areas under vegetables in recent years in all categories of farms have stabilized at the level of 65-70 thousand hectares, including in households - 46-50 thousand hectares, in farms - 10-11 thousand hectares. In the last 20 years, there is a positive trend of progressive increase in production in farms, the yield of vegetable products in which in 2018 by 64 and $31 \%$ exceeded the same indicator for agricultural organizations and farms, respectively. In the total structure of the gross harvest of vegetables on the farms of the population accounts for about $67-69 \%$, farm - 16-19\%, agricultural organizations $-13-15 \%$. Production of vegetables per capita in recent years has fluctuated at the level of $178-206 \mathrm{~kg}$ (at the rate of $146 \mathrm{~kg}$ ). The Republic fully provides itself with vegetables, in addition, vegetables are exported. More than 60 vegetable stores have been built in the country, but most of them require significant reconstruction. Currently, there is also an increase in the production of canned fruits and vegetables. Thus, the domestic market of vegetables is almost completely provided with products of its own production. To improve the efficiency of vegetable growing of the Republic of Belarus on the basis of specialization and concentration of production it is necessary to improve the organization of the whole vegetable subcomplex, including geographical location, specialization, and the structure of production of vegetables, including a strengthening material-technical base of processing and storage, improving the procurement of commodity products, expanding the range and improving the quality of vegetables.

Key words: The Republic of Belarus, vegetable, vegetable subcomplex, the agricultural organizations, peasant farms of the population.

For citing: Autko A.A., Butov I.S. Vegetable growing of the Republic of Belarus. Potato and Vegetables. 2020. No2. Pp. 12-15. (In Russ.). https://doi.org/10.25630/PAV.2020.18.2.002
P еспублика Беларусь расположена в Восточной Европе, ее тер-

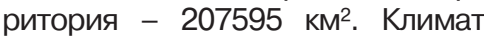
Беларуси умеренно континентальный, на западе переходный от морского к континентальному, формирующийся под влиянием воздушных масс Атлантики. В зимний период нередки оттепели. Средняя летняя температура колеблется от $17^{\circ} \mathrm{C}$ на севере (июль), до $18-19^{\circ} \mathrm{C}$ на юге, а зимняя - от $-4,5^{\circ} \mathrm{C}$ на юго-западе до $-8{ }^{\circ} \mathrm{C}$ на северо-востоке (январь). Осадки выпадают равномерно, с возрастанием с юга на север - от 500 мм на юге, до 800 мм на северо-за- паде. Максимальное количество осадков обычно выпадает в осенне-зимний период. В лесных районах толщина снежного покрова может составлять 1-1,2 м. Главные реки Беларуси: Днепр и его притоки - Припять, Сож и Березина, а также Западная Двина, Неман и Западный Буг. Полесье, находящееся на юге, представляет собой крупнейший в Европе район болот и заболоченных земель.

Территория страны в основном равнинная. Редкие возвышенности, относящиеся к Белорусской гряде, почти не превышают высо- ты 300 м. Примерно на 60\% территории Беларуси преобладают дерновоподзолистые почвы разного механического состава и степени оподзоленности, в западной части выделяются почвы, близкие к бурым лесным, и глеево-подзолистые почвы, по низинам (особенно в Полесье) - дерново-болотные и болотные. По механическому составу почвы делятся на глинистые $(0,05 \%)$, суглинистые $(31,6 \%)$, супесчаные $(27,75 \%)$, песчаные (31\%), торфяные $(9,6 \%)$. В долинах крупных рек распространены аллювиально-луговые почвы. 


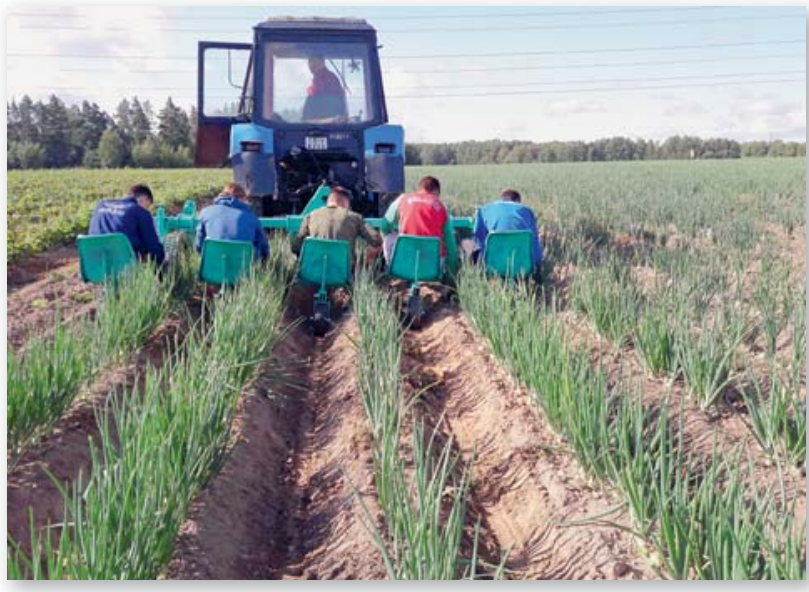

Прополка лука с помощью агрегат-платформы АП-5 неплоды, зеленные). Условия для ежегодных гарантированных сборов теплолюбивых культур (томат, огурец) в открытом грунте имеются только в юго-восточных и юго-западных районах республики. На остальной территории гарантированные урожаи этих культур наиболее возможны в теплицах, под пленочными укрытиями и в утепленном грунте. В связи с этим, Полесье стало крупным овощеводческим кластером производства овощей.

Суглинистые и супесчаные почвы более активно задействованы в сельском хозяйстве. Большая часть почв кислые, от сильнокислых в гидроморфных болотных почвах верхового типа до слабокислых и близких к нейтральной кислотности.

Совокупная площадь с.- х. земель - 8460,1 тыс. га, из них около 16,5\% земель мелиорированы. Из 5712,3 тыс. га пахотных земель 4991,5 тыс. га находятся в пользовании с.- х. организаций, 532,4 тыс. га - в пользовании граждан, из которых 640 тыс. га отведено под личные подсобные хозяйства, 137,4 тыс. га - в пользовании фермерских хозяйств [1].

Природно-климатические условия Беларуси благоприятны для возделывания холодостойких овощных культур (все виды капусты, столовые кор- га, в том числе в хозяйствах населения - 46-50 тыс. га, в КФХ - 10-11 тыс. га. Относительно 2000 года общие посевы под овощами снизились на $36 \%$, в том числе в с.- х. организациях - более чем в три раза (с 17,8 тыс. га до 5,9 тыс. га). В тоже время в крестьянских (фермерских) хозяйствах посевы увеличились почти в пять раз, в результате чего их доля в общей структуре посевов овощей возросла с 2,2\% до 16,2\% (табл.).

В последние годы валовой сбор овощей в республике составляет порядка 1700-1900 тыс. т. Относительно 2000 года валовой сбор увеличился на $26,6 \%$ и составил в 2018 году 1746 тыс. т. В последние 20 лет прослеживается положительная тенденция поступательного наращивания производства в КФХ, урожайность овощной продукции в которых в 2018 году на 64 и 31\% превышала аналогичный показатель по c. - х. организациям и хозяйствам населения соответственно. В общей структуре валового сбора овощей на хозяйства населения приходится порядка 67-69\%, КФХ - 16-19\%, с.- х. организации - 13-15\%.

За 2010-2018 годы посевные площади хозяйств всех категорий, занятые овощными культурами, сократились на 27,2\%, а урожайность последних, наоборот, выросла на $7,3 \%$, достигнув значений 62,4 тыс. га и 26,5 т/га соответственно. Урожайность овощей во всех с.- х. организациях республики за истекший девятилетний период выросла почти в 1,3 раза.

\section{Динамика основных производственных показателей возделывания овощей в Республике Беларусь, 2000-2018 годы}

\begin{tabular}{|c|c|c|c|c|c|c|c|c|}
\hline \multirow{2}{*}{ Показатель } & \multicolumn{7}{|c|}{ Годы } & \multirow{2}{*}{$\begin{array}{c}2018 \text { год } \\
\text { в\% } \\
\text { к } 2000 \text { году }\end{array}$} \\
\hline & 2000 & 2005 & 2010 & 2015 & 2016 & 2017 & 2018 & \\
\hline \multicolumn{9}{|c|}{ Посевная площадь, тыс. га } \\
\hline Хозяйства всех категорий & 97,8 & 88,3 & 85,7 & 66,3 & 65,7 & 63,2 & 62,4 & 63,8 \\
\hline С.-х. организации & 17,8 & 13,4 & 15,6 & 8,4 & 7,1 & 6,3 & 5,9 & 33,1 \\
\hline$K(\Phi) X$ & 2,2 & 3,5 & 6,7 & 10,0 & 11,2 & 10,1 & 10,1 & в 4,6 раза \\
\hline Хозяйства населения & 77,8 & 71,4 & 63,4 & 47,9 & 47,4 & 46,9 & 46,4 & 59,6 \\
\hline \multicolumn{9}{|c|}{ Валовой сбор, тыс. т } \\
\hline Хозяйства всех категорий & 1379 & 2007 & 2335 & 1687 & 1891 & 1959 & 1746 & 126,6 \\
\hline С.-х. организации & 262 & 220 & 301 & 252 & 275 & 263 & 228 & 87,1 \\
\hline$K(\Phi) X$ & 32 & 60 & 142 & 266 & 347 & 366 & 324 & в 10,1 раза \\
\hline Хозяйства населения & 1085 & 1727 & 1891 & 1168 & 1270 & 1330 & 1194 & 110,1 \\
\hline \multicolumn{9}{|c|}{ Урожайность, т/га } \\
\hline Хозяйства всех категорий & 13,4 & 20,8 & 24,7 & 24,5 & 27,6 & 29,5 & 26,5 & 197,8 \\
\hline С.- х. организации & 14,6 & 14,7 & 16,0 & 18,5 & 24,4 & 25,0 & 20,5 & 140,4 \\
\hline$K(\Phi) X$ & 14,5 & 16,5 & 24,7 & 29,7 & 33,3 & 38,2 & 33,7 & 232,4 \\
\hline Хозяйства населения & 13,1 & 21,7 & 26,5 & 24,4 & 26,8 & 28,4 & 25,8 & 196,9 \\
\hline
\end{tabular}




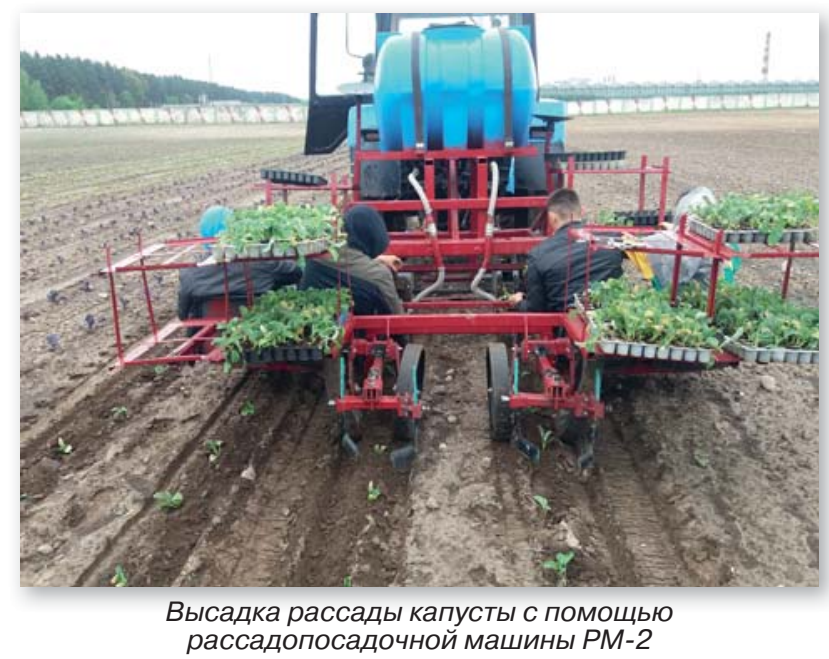

В республике исторически сложилась и действует соответствующая природно-экономическим условиям специализация производства овощей. Существует пригородное овощеводство и специализированные сырьевые овощеводческие зоны отдельных перерабатывающих предприятий. Товарным овощеводством занимаются крупные специализированные и фермерские предприятия, где овощеводство - главная отрасль, и с. - х. предприятия, в которых производство овощей - дополнительная отрасль. Процесс углубления специализации овощеводства характеризуется концентрацией производства овощей в отдельных с.- х. предприятиях. В региональном аспекте наибольший удельный вес в валовом сборе овощей занимают хозяйства Минской области: этот показатель у них составляет в последние годы порядка 24-26\%, Брестской $20-23 \%$, в то же время доля хозяйств Гомельской области находится на уровне $16-17 \%[1,2,3]$.

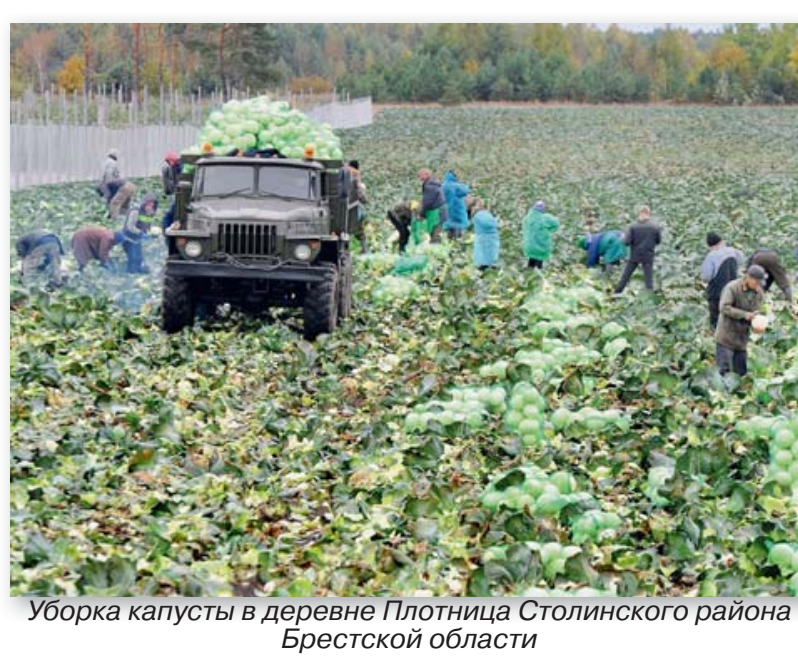

Производство овощей на душу населения в последние годы колебалось на уровне 178-206 кг (при норме 146 кг). Республика полностью обеспечивает себя овощами, кроме того овощи поставляются на экспорт. Однако рынок страны не сбалансирован по ассортименту и качеству овощной продукции $[4,5]$.

В соответствии с Госпрограммой развития аграрного бизнеса в Республике Беларусь, утвержденной постановлением Совета Министров Республики Беларусь № 196 от 11 марта 2016 года, планируется сконцентрировать производство овощей в организациях, осуществляющих деятельность по производству овощей (до 80\% от общего объема производства) в общественном секторе, а также нарастить производство овощей к концу 2020 года до 1600 тыс. т в хозяйствах всех категорий, из них в общественном секторе - 600 тыс. т. Вторая цель Госпрограммы фактически выполнена (фактический валовой сбор в 2018 году уже составлял 1746 тыс. т.). А вот первая цель в настоящее время практически недостижима, поскольку производство овощей в Республике Беларусь сосредоточено в основном в частном секторе (почти 90\% общего объема производства).

Наряду с крупными товарными с.- х. организациями различных организационно-правовых форм успешно развиваются мелкие производители с.- х. про- дукции, представленные субъектами малого предпринимательства и различными формами хозяйств населения. Особенно хорошо представлено мелкотоварное производство овощей в южных районах Белорусского Полесья: Столинском, Ивановском, Малоритском, Пинском и других районах. Почвенно-климатические условия этого региона позволяют успешно и продуктивно возделывать 60-65 видов овощных культур. Огромное значение играет и то, что на Полесье уже сложились соответствующие исторические традиции у населения по выращиванию овощей. Например, деревня Ольшаны Столинского района известна на всю страну своими производителями огурцов, томатов и моркови. За деревней даже закрепилось неофициальное название «огуречной столицы Беларуси». Также планируется двукратное увеличение производства овощей в пойме реки Припять, причем как в с. - х. организациях, так и КФХ и ЛПХ. Однако, несмотря на очевидно первостепенное значение мелкотоварного овощеводства этого региона для страны, конкретных показателей по хозяйствам Минисельхоз РБ в официальной статистике не приводит, так как большинство хозяйств не оформлены юридически и частично относится к хозяйствам населения, а частично $\mathrm{K}$ КФX.

В прошлом году максимальный валовой сбор овощей в фермерских хозяйствах обеспечили КФХ Брестской области - 224,8 тыс. т (при средней урожайности 46,6 т/га), тогда как в Витебской области общий валовой сбор был всего лишь 11,2 тыс. т (при средней урожайности 29,9 т/га). В то же время, в 2018 году белорусские фермеры обеспечили сбор 18,5\% овощей и 6,4\% картофеля, хотя в их пользовании находится только 2,3\% всех сельхозугодий страны (в среднем 73,5 га на одно хозяйство). На картофель и овощи пришлось 54,8\% всех объемов производства. Доля фермеров в общем объеме сельского хозяйства страны в последние годы выросла по всем группам, но особенно - в производстве овощей и картофеля. По сравнению с 2010 годом по овощам она увеличилась с 6,1 до 18,5\%, по картофелю - с 2 до 6,4\% [6]. Только у 16 фермерских семей страны уделы превышают 1 тыс. га. К крупнейшим фермерским хозяйствам страны, специализирующимся на овощах и картофеле, относятся, например, такие хозяйства как «Цнянские экопродукты» (Логойский район), 
«Родник» (Шумилинский район), ФХ «Новицких» (Лунинецкий район), «Юлиан» (Лунинецкий район), «КФХ Ринга С. В.» и «Ринг-Агро» (Дрибинский и Чаусский районы), «ФХ Пакуша И. А.» (Молодечненский район), «Вармас» (Витебский район), ФХ «Горизонт» (Мостовский район). Однако нехватка земли и административные препоны по ее получесдерживающих развитие фермерства в Беларуси [6, 7].

Урожайность основных культур в фермерских хозяйствах значительно опережает аналогичный показатель в хозяйствах всех других типов и составляет по капусте 45,2 т/га, по моркови 45,1 т/га, по свекле 30,4 т/га, по луку 24,7 т/га [1].

C. - х. организации и КФХ peaлизуют произведенную продукцию через собственные торговые сети, посредством маркетинговых служб, нию - одни из главных факторов, а также по прямым договорам. Ряд c. - х. организаций располагает оборудованием по предпродажной подготовке продукции и картофеля (очистка, сортировка, калибровка, мойка, сушка, фасовка в различную тару и т.д.) [3].

В стране построено более 60 овощехранилищ, однако большинство из них требует существенной реконструкции. В республике на ПООО «Техмаш» создано более 20 видов специализированных видов машин для овощеводства.

В Республике Беларусь на переработку направляется около 10\% выращенных овощей. В настоящее время отмечен рост производства плодоовощных консервов. Однако их производство сдерживается сложностью реализации продукции на отечественном рынке так как в рационе белорусских потребителей, особенно сельского населения, значи- тельный удельный вес имеют овощи собственного производства $[6,7,8$, 9].

\section{Выводы}

Для повышения эффективности овощеводства Республики Беларусь на основе специализации и концентрации производства необходимо совершенствование организации всего овощного подкомплекса, включающую территориальное размещение, специализацию и структуру производства овощей, в том числе укрепление материально-технической базы производства переработки и хранения, улучшение организации закупок товарной продукции, расширение ассортимента и улучшение качества овощей. Необходим также перевод производства овощей в систему экологизированного земледелия для чего впервые среди стран СНГ создан полный комплекс специализированных машин.

\section{References}

1.Сельское хозяйство Республики Беларусь: статистический сборник / Национальный статистический комитет Республики Беларусь. Минск, 2019. 212 с.

2.Шпак А. и др. Тенденции и направления развития плодоовощного подкомплекса Республики Беларусь // Аграрная экономика. 2017. №9. С. 48.

3.Бондарович Н.А. Пути повышения эффективности плодоовощного комплекса АПК // Правовые, экономические и социально-гуманитарные науки: сборник научных трудов. 2016. Вып. 1. С. $12-15$.

4.Белявская С.Л. Повышение конкурентоспособности плодоовощной продукции за счет использования мирового опыта в хозяйствах республики // Зарубежное научное сотрудничество: опыт и возможности аграрных вузов: материалы Международной научной конференции, 17-18 мая 2012 года. Минск, 2012. С. 105-109.

5.Шабуня О.Н. Состояние плодоовощной консервной отрасли и проблемы ее развития в Республике Беларусь // Научноинновационная деятельность в агропромышленном комплексе: сборник научных статей. Минск, 2011. Ч. 2. С. 253-255.

6.Макрак С.В. Научные основы совершенствования системы управления материально-денежными ресурсами при производстве сельскохозяйственной продукции // Вес. Нац. акад. навук Беларусі. Сер. аграр. навук. 2019. Т. 57. №2. С. 135-150.

7.Гордзялковский А. Картофельные короли и морковные бароны. Топ-16 фермеров-тысячников Беларуси // Бизнес-ревю. 2019. №4. C. $58-62$.

8.Шанько О.Ю. Перспективы кооперации в плодоовощном подкомплексе на примере предприятий Минской области // Агропанорама. 2015. № 1. С. 29-33.

9.Аутко А.А., Гануш Г.И., Долбик Н.Н. Приоритеты современного овощеводства. Минск: УП Технопринт, 2003. 156 с.

\section{Об авторах}

Аутко Александр Александрович, доктор с.-х. наук, профессор, гл.н.с. кафедры механизации с.-х. производства, УО «Гродненский государственный аграрный университет». E-mail: autko-alexander@rambler.ru

Бутов Илья Станиславович, канд. с.-х. наук, редактор-журналист, журнал «Картофель и овощи». E-mail: illiabutov@gmail.com
1.Agriculture of the Republic of Belarus: statistical compendium. National statistical Committee of the Republic of Belarus. Minsk, 2019. 212 pp. (In Russ.).

2.Shpak A. \& al. Trends and directions of development of fruit and vegetable subcomplex of the Republic of Belarus. Agrarian economy. 2017. №9. Pp. 48 (In Russ.).

3.Bondarovich N.A. Ways to improve the efficiency of the fruit and vegetable complex of agriculture. Legal, economic and socialhumanitarian Sciences: collection of scientific works. 2016. Vol. 1. Pp. 12-15 (In Russ.).

4.Beljavskaja S.L. Improving the competitiveness of fruits and vegetables through the use of world experience in the farms of the Republic. Foreign scientific cooperation: experience and opportunities of agricultural universities: proceedings of the International scientific conference, may 17-18, 2012. Minsk, 2012. Pp. 105-109 (In Russ.).

5.Shabunja O.N. The state of the fruit and vegetable canning industry and the problems of its development in the Republic of Belarus. Scientific and innovative activity in the agro-industrial complex: collection of scientific articles. Minsk, 2011. Part. 2. Pp. 253-255 (In Russ.).

6.Makrak S.V. Scientific basis for improving the management system of material and monetary resources in the production of agricultural products. Maintained by the National Academy of Sciences of Belarus. Agricultural Sciences series. T. 57. №2. Pp. 135-150 (In Russ.).

7.Shan'ko O.Ju. Prospects of cooperation in the fruit and vegetable subcomplex on the example of enterprises of the Minsk region // Agropanorama. 2015. № 1. Pp. 29-33 (In Russ.).

8.Gordzjalkovskij A. Potato kings and carrot barons. Top 16 thousand farmers in Belarus. Business review. 2019. №4. Pp. 5862 (In Russ.).

9.Autko A.A., Ganush G.I., Dolbik N.N. Priorities of modern vegetable growing. Minsk: UP Tehnoprint, 2003. 156 p. (In Russ.).

\section{Author details}

Autko A.A., D.Sci. (Agr.), chief research fellow of Department of mechanization of agricultural production of El Grodno State Agrarian University. E-mail: autko-alexander@rambler.ru

Butov I.S., Cand. Sci. (Agr.), editor-reporter, Potato and Vegetables journal. E-mail: illiabutov@gmail.com 